\title{
OF MICE AND METALS: THE CORPORATION, WHY I STOPPED FEARING IT AND STARTED TO LOVE
}

IT.

Otavio M. Fortini, Milo Information Services Corp., Pittsburgh, Pennsylvania, USA

Joseph Thaman, PNC Capital Markets, Pittsburgh, Pennsylvania, USA

Lawrence Whyte, BNY Mellon Economic Capital Analysis, Pittsburgh, Pennsylvania, USA

dx.doi.org/10.18374/JIFS-13-1.2

\begin{abstract}
Business strategy is usually seen as generated from inside the business. In reality, businesses adapt to conditions from the outside to survive. This paper uses the aluminum industry to assert this simple but always overlooked fact. Companies in the aluminum industry are often older than a hundred years and their behavior throughout their lives sheds plenty of light into the strategies followed by surviving players. This paper gives overwhelming evidence of the role played by other institutions else than the business organization in setting the tone of Corporate strategies. The reader should pay special attention to the sections describing the growth of the aluminum industry in the 1930s and the recent rise of the powerful Russian player. It is shown by historical example that State players have much more influence over the behavior and evolution of large Corporations than market forces or actions by in-house decision makers.
\end{abstract}

Keywords: strategy, strategy analysis, innovation, corporate history, aluminum history, Porter model, five forces model, Schumpeter, long term sustainability, competitive reaction 